\title{
TINGKAT PENGETAHUAN ASI EKSKLUSIF PADA IBU PRIMIPARA DI DUSUN PUNDONG KELURAHAN SRIHARDONO KECAMATAN PUNDONG KABUPATEN BANTUL
}

\author{
Endah Puji Astuti, Fara Adhiba \\ Program Studi D3Kebidanan STIKES A. Yani Yogyakarta
}

\begin{abstract}
Background : Exclusive breastfeeding is the infant only breastmilk alone were given no food or liquid other than drugs, vitamins, and minerals. Primiparous mothers lack of knowledge about exclusive breastfeeding is good general, the definition of breastfeeding, benefit of breastfeeding, composition of breastfeeding, and how breastfeeding may be influenced by several factor, such as age, education, work, and resources, so that it can directly affect the success of exclusive breasfeeding.
\end{abstract}

Objective : determine the level of knowledge of exclusive breastfeeding in primipara mothers.

Methods : this research used descriptive method. Sampling by using total sampling. A large sample of 60 respondent. Analysis using descriptive.

Result : based on the result of the research, found most respondent are mother with less knowledge of exclusive breastfeeding, as many as 36 respondents $(60,0 \%)$. Primiparous mothers with the level of knowledge about the definition of breastfeeding exclusive less category as much as 41 respondents (68,3\%). Primiparous mothers with the level of knowledge about the benefits of breastfeeding exclusive good category as much as 32 respondents $(53,3 \%)$. Primiparous mothers with the level of knowledge about the composition of breastfeeding exclusive enough category as much as 33 respondents $(55,0 \%)$. Primiparous mothers with the level of knowledge about how breastfeeding may be influenced exclusive less category as much as 40 respondents $(66,7 \%)$.

Conclusion : in this study indicate the level of knowledge of mothers who are less due to maternal characteristic ( occupation and resources), and therefore can be expected in health personel actively provide counseling on exclusive breastfeeding.

Keyword : Mother knowledge about exclusive breastfeeding, primiparous mother.

\section{PENDAHULUAN}

Hasil Survei Sosial Ekonomi
Nasional (Susenas) tahun 2009-2014,
presentase jumlah pemberian ASI
eksklusif di Indonesia pada seluruh bayi
dibawah 6 bulan ( $0-6$ bulan) meningkat
dari $58,9 \%$ pada tahun 2009 menjadi
$61,3 \%$ pada tahun 2014 , begitu juga
dengan bayi yang mendapat ASI eksklusif
terus menerus dari usia 0 sampai 6 bulan

juga meningkat dari 19,5\% tahun 2009 menjadi $34,3 \%$ pada tahun 2014 . Hal ini menunjukkan adanya peningkatan pengetahuan para ibu untuk menyusui bayinya, namun angka yang masih di bawah $50 \%$ menunjukkan adanya kendala yang dialami ibu yang menyebabkan pengetahuan tentang pentingnya ASI eksklusif dan pemberiannya terganggu. ${ }^{1}$ Hasil survey Susenas tahun 2009-2014 juga menyebutkan, prevalensi pemberian 
ASI eksklusif di 5 kabupaten menyebutkan bahwa kabupaten Bantul merupakan wilayah yang prevalensinya menurun pada tahun 2013 dari $63,51 \%$ menjadi $62,05 \%$ pada tahun 2014 , terutama di dusun Pundong masih terbilang rendah, yaitu sebesar $<50 \%$ (Profil Kesehatan Kabupaten Bantul 2014). Hal ini sungguh ironis mengingat bahwa ASI merupakan hak asasi bayi yang wajib diberikan oleh ibu, namun para ibu tidak memberikan ASI eksklusif hanya karena terkendala pengetahuannya yang kurang.

Berdasarkan studi pendahuluan yang telah dilakukan di Dusun Pundong, Kelurahan Srihardono, Kecamatan Pundong, Kabupaten Bantul, didapatkan informasi bahwa dari 10 ibu yang memiliki bayi berumur $<6$ bulan, 8 diantaranya tidak memberikan lagi ASI Eksklusif, mereka mulai memberikan madu, pisang, dan bubur halus sejak usia bayi 2 bulan dikarenakan tidak tahu apa itu ASI eksklusif, sedangkan 2 ibu lainnya masih memberikan ASI Eksklusif sampai saat ini. Di dusun tersebut juga jarang sekali dilakukan penyuluhan tentang ASI eksklusif, mereka mendapatkan informasi tentang ASI hanya sekilas ketika mereka selesai bersalin di tempat bidan atau Rumah Sakit, itupun tidak dikontrol lagi oleh tenaga kesehatan setempat, oleh sebab itu, penulis tertarik untuk mengadakan penelitian tentang tingkat pengetahuan ASI eksklusif pada ibu primipara di Dusun Pundong.

\section{BAHAN DAN CARA PENELITIAN}

Penelitian ini menggunakan metode deskriptif. Penelitian ini dilaksanakan di Dusun Pundong, Kelurahan Srihardono, Kecamatan Pundong, Kabupaten Bantul. Penelitian ini dilaksanakan pada tanggal 13 - 22 Juni 2015. Populasi berjumlah 60 orang, menggunakan total sampling. Data didapatkan dari pengisian kuesioner.

\section{HASIL DAN PEMBAHASAN}

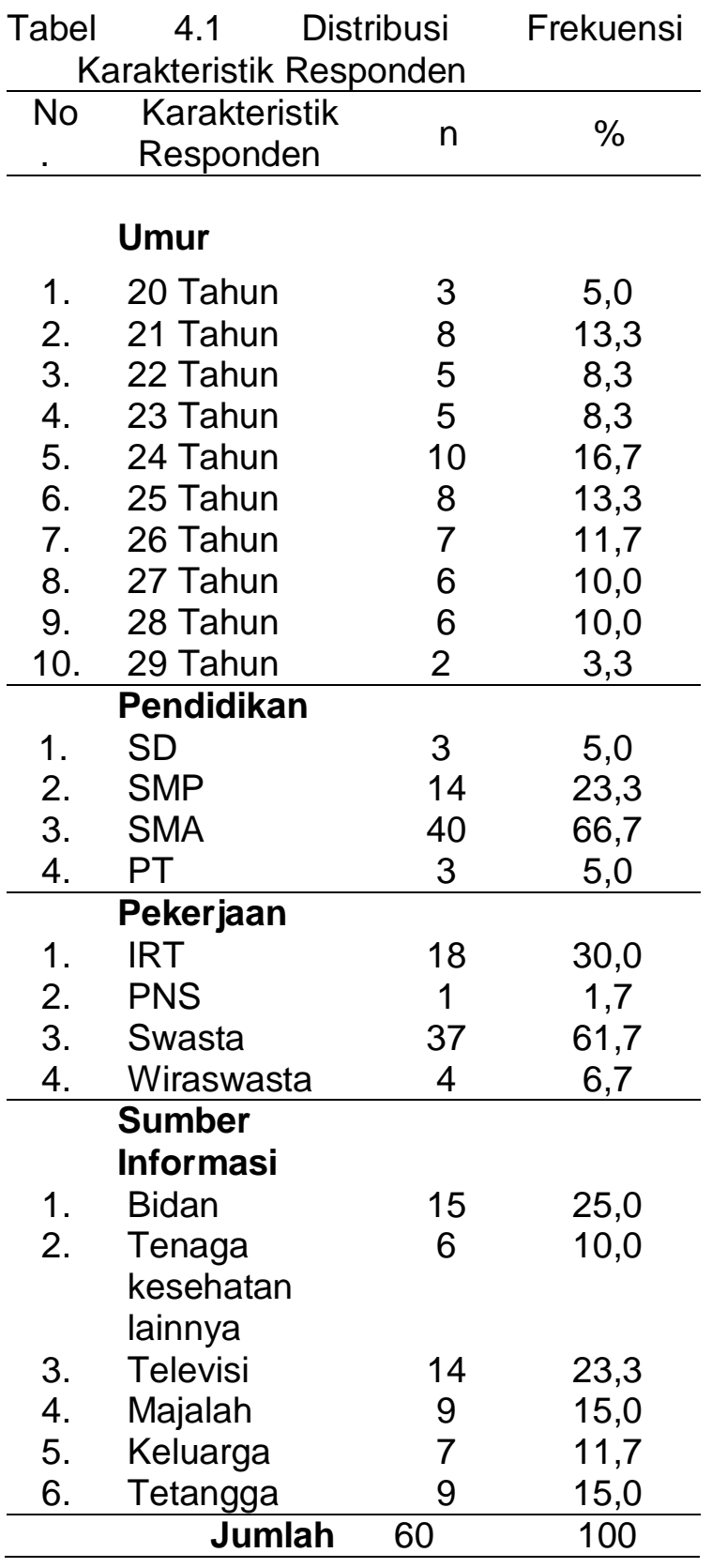


Tabel 4.2. Pemberian ASI eksklusif

\begin{tabular}{clcc}
\hline No. & Pemberian ASI & $\mathrm{n}$ & $\%$ \\
\hline 1. & Eksklusif & 28 & 46,7 \\
2. & Tidak eksklusif & 32 & 53,3 \\
\hline
\end{tabular}

Tabel 4.3. Distribusi Frekuensi

Berdasarkan Tingkat Pengetahuan

Tentang ASI Eksklusif Pada Ibu

Primipara

\begin{tabular}{|c|c|c|c|}
\hline No & $\begin{array}{l}\text { Tingkat Pengetahuan } \\
\text { Tentang ASI Eksklusif } \\
\text { Pada lbu Primipara }\end{array}$ & $\mathrm{n}$ & $\%$ \\
\hline & Baik & 7 & 11,7 \\
\hline & Cukup & 17 & 28,3 \\
\hline & Kurang & 36 & 60,0 \\
\hline & Jumlah & 60 & 100 \\
\hline
\end{tabular}

Tabel 4.4. Distribusi Frekuensi

Berdasarkan Tingkat Pengetahuan

Tentang Definisi ASI Eksklusif Pada lbu Primipara

\begin{tabular}{|c|c|c|c|}
\hline No & $\begin{array}{c}\text { Tingkat Pengetahuan } \\
\text { Tentang Definisi ASI } \\
\text { Eksklusif Pada lbu } \\
\text { Primipara }\end{array}$ & $n$ & $\%$ \\
\hline & Baik & 9 & 15,0 \\
\hline & Cukup & 10 & 16,7 \\
\hline & Kurang & 41 & 68,3 \\
\hline & Jumlah & 60 & 100 \\
\hline
\end{tabular}

Sumber : Data Primer diolah (2015

Tabel 4.5. Distribusi Frekuensi

Berdasarkan Tingkat Pengetahuan

Tentang Manfaat ASI Eksklusif Pada lbu Primipara

\begin{tabular}{|c|c|c|c|}
\hline No & $\begin{array}{c}\text { Tingkat Pengetahuan } \\
\text { Tentang Manfaat ASI } \\
\text { Eksklusif Pada Ibu } \\
\text { Primipara }\end{array}$ & $\mathrm{n}$ & $\%$ \\
\hline & Baik & 32 & 53,3 \\
\hline & Cukup & 14 & 23,3 \\
\hline & Kurang & 14 & 23,3 \\
\hline & Jumlah & 60 & 100 \\
\hline
\end{tabular}

Sumber : Data Primer diolah (2015)
Tabel 4.7. Distribusi Frekuensi

Berdasarkan Tingkat Pengetahuan

Tentang Komposisi ASI Eksklusif

Pada Ibu Primipara

\begin{tabular}{ccc}
\hline $\mathrm{N} \quad \begin{array}{c}\text { Tingkat Pengetahuan } \\
\text { Tentang Komposisi } \\
\text { ASI Eksklusif Pada lbu } \\
\text { Primipara }\end{array}$ & $\mathrm{n}$ & $\%$ \\
\hline Baik & 8 & 13,3 \\
Cukup & 33 & 55,0 \\
Kurang & 19 & 31,7 \\
\hline Jumlah & 60 & 100 \\
\hline Sumber : Data Primer diolah (2015) &
\end{tabular}

Tabel 4.8. Distribusi Frekuensi Berdasarkan Tingkat Pengetahuan Tentang Cara Pemberian ASI Eksklusif Pada lbu Primipara

No Tingkat Pengetahuan

Tentang Cara Pemberian

ASI Eksklusif Pada lbu n $\quad \%$ Primipara

\begin{tabular}{ccc}
\hline Baik & 12 & 20,0 \\
Cukup & 8 & 13,3 \\
Kurang & 40 & 66,7 \\
\hline Jumlah & 60 & 100 \\
\hline
\end{tabular}

Sumber : Data Primer diolah (2015)

Berdasarkan hasil penelitian yang telah dilakukan, dapat diketahui bahwa tingkat pengetahuan ibu primipara tentang ASI eksklusif secara umum sebagian besar adalah kurang yaitu sebesar 36 responden $(60,0 \%)$ dan sebagian kecil memiliki pengetahuan yang baik 7 responden $(11,7 \%)$. Begitu halnya dengan tingkat pengetahuan ibu primipara tentang definisi ASI, didapatkan hasil sebagian besar responden berpengetahuan kurang yaitu 41 responden $(68,3 \%)$ dan sebagian kecil berpengetahuan baik yaitu 9 responden (15,0\%), diketahui pertanyaan yang paling tidak bisa dijawab oleh responden adalah pertanyaan tetap ASI eksklusif meskipun bayi diberikan air putih, madu atau teh, sebagian besar responden menjawab benar, jawaban tersebut menunjukkan bahwa memberikan makanan atau minuman sebelum bayi berusia 6 bulan mereka anggap tetap ASI eksklusif. Juga dengan tingkat pengetahuan ibu primipara tentang cara 
pemberian ASI didapatkan hasil kurang yaitu sebesar 40 responden (66,7\%), diketahui pertanyaan yang tidak bisa dijawab oleh responden yaitu pada ibu bekerja pemberian ASI dapat diimbangi dengan pemberian susu formula sebagian besar responden menjawab benar. Padahal pengertian ASI eksklusif menurut Roesli, 2010 adalah bayi hanya diberi ASI saja dari usia 0-6 bulan tanpa diberi makanan atau minuman tambahan apapun.

Hasil penelitian yang telah dilakukan juga menunjukkan bahwa tingkat pengetahuan ibu primipara tentang manfaat ASI adalah baik yaitu sebesar 32 responden (53,3\%). Menurut Roesli, 2008 manfaat ASI adalah eksklusif bagi bayi adalah sebagai nutrisi, meningkatkan daya tahan tubuh, dan kecerdasan otak bayi, sedangkan bagi ibu adalah mengurangi resiko terjadinya anemia, cepat langsing, hemat, dan praktis, jika dilihat dari pertanyaan yang paling tidak bisa dijawab oleh responden tentang manfaat ASI yaitu pertanyaan memberi ASI membuat repot, dan sebagian besar responden juga menjawab benar, jawaban tersebut menunjukkan kurangnya kesadaran ibu dalam pemberian ASI karena mereka menganggap memberikan ASI eksklusif adalah kegiatan yang membuat repot. Hasil penelitian yang telah dilakukan juga menunjukkan bahwa tingkat pengetahuan ibu primipara tentang komposisi ASI adalah cukup yaitu sebesar 33 responden (55,0\%). Menurut Roesli, 2008, komposisi ASI sangat khusus sehingga dari masing-masing ibu berbeda komposisi ASI nya, misal pada ibu yang melahirkan bayi cukup bulan, komposisinya berbeda dengan ibu yang melahirkan secara prematur. Jika dilihat dari pertanyaan yang paling tidak bisa dijawab oleh responden tentang komposisi ASI yang menyebutkan komposisi ASI sama dari waktu ke waktu.

Dari hasil penelitian diatas dapat disimpulkan sebagai berikut, menurut Soekanto (2007) pengetahuan dipengaruhi oleh faktor-faktor seperti pendidikan, informasi, budaya, pengalaman sosial, dan ekonomi dari jawaban responden, responden dengan pengetahuan kurang mayoritas mendapatkan informasi dari televisi dan bekerja sebagai pekerja swasta. Televisi memang sumber yang valid, namun responden hanya bisa melihat dan mendengar tanpa bisa bertanya sehingga responden tidak bisa memahami sepenuhnya apa yang disampaikan narasumber di televisi, sedangkan pekerjaan ibu dapat mempengaruhi pengetahuan ibu yang kurang karena ibu yang bekerja harus membagi waktu sehinga tidak bisa secara penuh tahu tentang ASI eksklusif secara umum baik definisi ASI, dan cara pemberian ASI, karena terbukti dari jawaban responden yang ada, usia responden yang kurang mayoritas 23-26 tahun, itu berarti dalam usia yang subur kemudian siap hamil dan menyusui tetapi justru berpengetahuan kurang. Begitu pula pendidikan, responden mayoritas berpendidikan SMA yang berarti tingkat pendidikannya sudah bagus namun justru berpengetahuan kurang. Dari hasil penelitian juga ditemukan kesamaan penelitian yang ditulis oleh Sri Wahyuni "Hubungan Antara Pengetahuan Dengan Sikap Ibu Primipara Mengenai Kenyamanan Dan Tekhnik Yang Benar Saat Menyusui Di Klinik Bersalin Mulia, Kubu Raya" dalam penelitian tersebut menunjukkan adanya hubungan antara pengetahuan dengan sikap ibu primipara mengenai kenyamanan dan tekhnik yang benar saat menyusui, juga didapatkan hasil kurangnya tingkat pengetahuan ibu mengenai tekhnik menyusui yang benar, dan dari 23 responden terdapat 10 orang responden bekerja sebagai ibu rumah tangga, 3 orang responden bekerja sebagai mahasiswa, 6 orang responden PNS dan 4 orang responden bekerja swasta. Dilihat dari pekerjaan responden, pada umumnya adalah ibu rumah tangga yang dimana proses menyusuinya ditemukan efektif, sedangkan ibu yang bekerja sebagai PNS dan pegawai swasta memiliki proses menyusui yang tidak efektif. Pekerjaan juga berpengaruh terhadap pengetahuan dan keefektifan proses menyusui. Menurut Roesli, 2010 
ibu dengan pengetahuan cukup akan berhasil memberi ASI eksklusif. Teori tersebut sesuai dengan hasil penelitian yang ada bahwa ibu yang masuk dalam kategori cukup hingga baik terbukti berhasil memberikan ASI secara eksklusif.

\section{KESIMPULAN}

Penelitian ini dilakukan untuk mengetahui gambaran tingkat pengetahuan ASI eksklusif pada ibu primipara di Dusun Pundong, Kelurahan Srihardono, Kecamatan Pundong, Kabupaten Bantul. Kesimpulan dari penelitian ini adalah sebagai berikut: Pengetahuan umum tentang ASI eksklusif pada ibu primipara sebagian besar kurang (60,0\%). Pengetahuan ibu primipara tentang definisi ASI eksklusif sebagian besar kurang (68,3\%). Pengetahuan ibu primipara tentang manfaat ASI eksklusif sebagian besar baik (53,3\%). Pengetahuan ibu primipara tentang kompoisi ASI eksklusif sebagian besar cukup (55,0\%). Pengetahuan ibu primipara tentang cara pemberian ASI eksklusif sebagian besar kurang $(66,7 \%)$

\section{DAFTAR PUSTAKA}

[RISKESDAS] Riset Kesehatan Dasar. 2010. Jakarta: Badan Penelitian dan Pengembangan Kesehatan, Departemen Kesehatan, Republik Indonesia

Afiati. (2008). Breastfeeding father. 11 Juni 2012. http://afiati.multiply.com/journal/ite $\mathrm{m} / 142 /$ BreasfeedingFather.html

Arikunto, S. (2006). Prosedur Penelitian Suatu Pendekatan Praktik, Jakarta: Rineka Cipta

Aritonang, I. 2006. Pemantauan pertumbuhan balita petunjuk praktis menilai status gizi dan kesehatan. Yogyakarta: Kanisius

Budiman \& Riyanto, A. (2014). Kapita Selekta Kuesioner: Pengetahuan dan Sikap Dalam Penelitin Kesehatan. Jakarta : Salemba Medika
Depkes RI. (2010). Pelatihan konseling menyusui: Panduan peserta.

Jakarta: Direktorat Jenderal Bina Kesehatan masyarakat

Dinas Kesehatan Daerah Yogyakarta. (2013). Profil Kesehatan Daerah Yogyakarta. Tersedia 14 Profil Kes.Prov.DIY 2012.Pdf (15 Januari 2015)

Dinas Kesehatan Kabupaten Bantul. (2014). Profil Kesehatan Kabupaten Bantul.Yogyakarta.RI

Dwi, W. 2006. Pengaruh pendidikan kesehatan tentang manajemen laktasi terhadap perubahan perilaku ibu pasca salin dalam memberikan ASI eksklusif. http://adln.lib.unair.ac.id/, diperoleh tanggal 19 Maret 2012

Hijriyati, Y. (2006). Pengaruh jenis persalinan terhadap peningkatan pengetahuan ibu mengenai tekhnik menyusui dengan benar. Jakarta : Puspa Swara

Huliana, M. 2010. Perawatan ibu pasca melahirkan. Jakarta : Puspa Swara

Marmi. 2012. Asuhan Kebidanan Pada Masa Nifas "Peuperieum Care". Yogyakarta : Pustaka Pelajar

Nainggolan, M. (2009). Pengetahuan ibu primigravida mengenai faktorfaktor yang mempengaruhi kualitas dan kuantitas ASI di Puskesmas Simalingkar Medan. Skripsi: tidak dipublikasikan

Nasution, N. 2012. Gambaran Persepsi Terhadap Puting Payudara Dan Pemberian ASI Pada lbu Primipara di Depok. Skripsi FIK UI

Nengah, S. 2010. Hubungah Pengetahuan lbu Tentang Cara Menyusui Dengan Pemberian ASI Eksklusif Pada lbu Primipara Di Wilayah Kerja Puskesmas Pugung Raharjo Lampung Timur. Skripsi FIK UTP

2010. Metodelogi Penelitian Kesehatan. Jakarta : Rineka Cipta. Jakarta

Notoatmodjo, S. 2007. Kesehatan Masyarakat IImu Dan Seni. Jakarta : Rineka Cipta. Jakarta 
Notoatmodjo, S. 2012.Metodelogi Penelitian Kesehatan. Jakarta: Rineka Cipta. Jakarta

Purwanti, H.S. (2004). Konsep penerapan ASI eksklusif: Buku saku untuk bidan. Jakarta: EGC.

Roesli, U. 2010. Mengenal ASI Eksklusif (seri 1). Jakarta : Trubus Agriwidya 2008. Inisiasi Menyusui Dini Plus ASI Eksklusif. Jakarta : Pustaka Bunda

2008. Bayi sehat berkat ASI eksklusif, makanan pendamping tepat dan imunisasi lengkap. Jakarta : PT. Elex Media Kompetindo

Sinaga, D.P. (n.d.). Bab 2: Tinjauan pustaka. 28 Oktober 2011.

http://repository.usu.ac.id/bitstream /123456789/26210/4/Chapter\%20II . $\mathrm{pdf}$

Siregar, A. (2004) Faktor-faktor yang mempengaruhi pemberian ASI oleh ibu melahirkan. Laporan Penelitian: tidak dipublikasikan.

Soetjiningsih. 2010. ASI petunjuk untuk tenaga kesehatan. Jakarta : EGC

Soekanto, S. 2007. Sosiologi Suatu Pengantar. Jakarta: Rajawali

Wahyuni, S. 2013. Hubungan Antara Pengetahuan Dengan Sikap Ibu Primipara Mengenai Kenyamanan Dan Tekhnik Yang Benar Saat Menyusui Di Klinik Bersalin Mulia Kubu Raya. Skripsi FIK UI

Walyani, dkk. 2015.Asuhan Kebidanan Masa Nifas \& Menyusui. Yogyakarta : PT. Pustaka Baru 